\section{ECONOMICS}

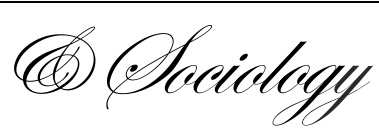

\author{
Amy Farmer, \\ University of Arkansas, \\ Fayetteville, USA, \\ E-mail:afarmer@walton.uark.edu \\ Raja Kali, \\ University of Arkansas, \\ Fayetteville, USA, \\ E-mail: rkali@walton.uark.edu
}

Received: February, 2016

1st Revision: April, 2016

Accepted: June, 2016

DOI: $10.14254 / 2071-$

789X.2016/9-2/15
Farmer, A., Kali, R. (2016), Collegiality in Organizations: An Economic

Approach to Organizational Citizenship Behavior, Economics and Sociology, Vol. 9,

No 2, pp. 220-231. DOI: 10.14254/2071-789X.2016/9-2/15

JEL Classification: Z13, L23, D23

\title{
COLLEGIALITY IN ORGANIZATIONS: AN ECONOMIC APPROACH TO ORGANIZATIONAL CITIZENSHIP BEHAVIOR
}

\begin{abstract}
We present an economic model of collegiality based on production with synergies in organizations. The model provides an adverse selection based explanation of corporate culture distinct from moral hazard or equilibrium selection rationales. The model yields positive correlation between corporate culture and collegiality and explains the observed correlation between the strength of corporate culture and the reliability of firm performance. The implications of the model are aligned with a rich literature in management and applied psychology on organizational citizenship behavior.
\end{abstract}

Keywords: synergies, collegiality, mutual insurance, corporate culture.

\section{Introduction}

Every factory, office, or bureau depends daily on a myriad of acts of helpfulness, gestures of goodwill, courtesy, conscientiousness, and other instances of what can be called organizational citizenship behavior (OCB). The study of OCB has produced a rich literature in management, with a large body of empirical work showing that OCB enhances organizational performance measured in various ways, such as the quantity and quality of output, team effectiveness, operating efficiency, and customer satisfaction (Podsakoff et al., 1997; Bergeron, 2007). But because citizenship behavior goes beyond formal role requirements and is difficult to measure, it is not easily governed by formal incentive schemes. One solution to the question of how to induce appropriate OCB is through corporate culture. Corporate culture solves the problem by specifying broad, tacitly understood rules "the way we do things around here" - for appropriate actions under unspecified contingencies (Camerer and Vepsalainen, 1988).

In this paper we focus on a specific subset of OCB that we refer to as collegiality and present a model of collegiality in an organization. The management literature broadly classifies OCB into the categories of helping behavior, sportsmanship, and civic virtue (Podsakoff and MacKenzie, 1997). Our notion of collegiality corresponds to helping behavior, elaborated by Podsakoff and MacKenzie as "Picking up the slack for others who are absent, or who have heavy workloads". The model provides an interpretation of corporate culture. Since imbibing the corporate culture of an organization takes time and effort, it is costly to join a collegial organization and reap the benefits of mutual insurance that it provides. As a result, individuals of distinct types sort into organizations with different costs 
of learning the corporate culture. Differences in learning costs across organizations can be interpreted as differences associated with the "thickness" or "strength" of corporate culture (Camerer and Vepsalainen, 1988; O'Reilly and Chatman, 1996). The model thus yields positive correlation between corporate culture and collegiality. Some organizations will have strong culture and high collegiality while others have weak culture and low collegiality. Since high collegiality in our model is associated with high mutual insurance, our model also explains the observed correlation between the strength of corporate culture and the reliability of firm performance (Sorensen, 2002).

Our model is inspired by real world evidence regarding corporate culture. For example, there are examples of organizations which go to considerable lengths to create a "differentiated" culture that is impressed upon new recruits (Coleman, 2013). Such norms are composed of the distinct vision, values, practices, and narratives that define the firm. McKinsey \& Company, for example, has a clearly articulated set of values that are prominently communicated to all employees and involve the way that firm vows to serve clients, treat colleagues, and uphold professional standards. McKinsey's articulation of its values includes "sustaining and caring for team members," which comes close to the notion of collegiality we use here.

The notion that some firms have "strong" culture and others have "weak" corporate culture is well-backed by detailed studies such as Flamholtz and Randle (2011). They note that companies differ in the extent to which they are effective in defining, communicating, and managing their culture. Companies where there is a clearly defined culture, where time is invested in communicating and reinforcing this culture, and where all employees are behaving in ways consistent with this culture are defined as having a strong culture. A strong culture is one that people clearly understand and can articulate. A weak culture is one that employees have difficulty defining, understanding, or explaining. They attribute the rise of firms such as Southwest Airlines and Starbucks to having strong culture, and the fall of firms like Ford and GM to weak culture.

The economic literature on corporate culture (which we discuss in section 2) takes the perspective that firms mostly use corporate culture as a means to reduce moral hazard problems or coordination failures associated with multiple equilibria. Our model is distinct from this literature in the sense that it provides an adverse selection based rationale for corporate culture. To the best of our knowledge, this perspective is novel to the literature.

The remainder of the paper is organized as follows. Section 1 provides a brief overview of the economic literature on corporate culture and the (mainly) psychology and management literature on organizational citizenship behavior (OCB). Section 2 introduces the model and analysis. Section 3 discusses implications. Section 4 concludes.

\section{Literature}

The economic literature on corporate culture can be divided broadly into two strands. The first strand views corporate culture as shared beliefs or shared preferences. This category of papers examines how beliefs and preferences of individuals affect equilibrium selection and agency problems. Papers in this category include contributions by Cremer (1993), Lazear (1995), and Van den Steen (2010). The idea of culture as shared beliefs and preferences is also the dominant definition in the psychology and management literature and is usually most associated with the work of Schein (1985). The second strand of contributions on the economics of corporate culture considers culture as a set of informal rules which enable equilibrium selection in a world of identical players in situations of multiple equilibria or unforeseen contingencies. These papers include Kreps (1990), Camerer and Vepsalainen (1988), Hermalin (2001), Carillo and Gromb (1999) and Rob and Zemsky (2002). 
In the psychology and management literature, there is an extensive body of work that considers organizational citizenship behavior, its antecedents, and its effects on firm performance since Bateman and Organ (1983) first coined the term. Smith et al. (1983) is an early contribution that argues that citizenship behavior is important in organizations and not easily explained by formal incentives. They classify OCB into two broad categories, helping behavior and conscientious citizenship, which is along the lines of civic virtue. Later contributions have examined the link between OCB and organizational performance. At the level of the work group, OCB is positively related to both quantity and quality of product output (Podsakoff et al., 1997), and contributes to team effectiveness (MacKenzie et al., 1996). At the organizational level, OCB has been shown to contribute to overall performance (Podsakoff and MacKenzie, 1994), operating efficiency and customer satisfaction (Walz and Niehoff, 1996). Podsakoff and Mackenzie (1997) review the literature and note that OCBs make important contributions to the variance of organizational effectiveness, although helping behaviors tend to have more systematic effects than either sportsmanship or civic virtue ${ }^{1}$.

There is also a well-established literature on homogeneity and selection of individuals into organizations that is aligned with our results. The psychology and management literature has studied how "fit" in terms of values and beliefs affects selection and outcomes such as job turnover and satisfaction (Chatman, 1991). In economics, Besley and Ghatak (2005) show how sorting in the labor market can lead employees to hold beliefs or preferences that are similar to those of the firm's manager. Along these lines, a paper by Dranove, Ramanarayan and Rao (2006) finds that doctors tend to sort according to medical approach or philosophy.

\section{The Model}

We present a model of collegiality in organizations that is set in the context of team production with synergies. Production takes place in two-person teams, and can take place either in the anonymous market or within an organization. Production teams within organizations obtain synergies, yielding higher output than when production takes place in the impersonal market. With some (exogenous) probability a worker is hit by an adverse shock each period which compromises his ability to contribute effort. In anonymous market production if any member of the team experiences a production shock then team output goes to zero. However, when production takes place within an organization, if one team member is hit by a negative shock then the partner can put in costly effort which partly compensates for the other's compromised effort. This yields positive joint output, albeit at a lower level than if both team members put in full effort. We refer to this kind of mutual insurance within an organization as collegiality or OCB. Thus, team production within an organization yields production synergies but comes with the requirement of collegial mutual assistance, while production in the anonymous market yields no synergies but neither does it require helping your partner with costly effort even when your partner contributes none.

We assume that joining an organization is costly. This is modeled as a simple entry fee, but is motivated by the notion that there are learning costs associated with imbibing the norms of a collegial organization, also referred to as corporate culture. These costs need to be incurred in order to be able to obtain production synergies within an organization.

We proceed below by first considering anonymous market production as the benchmark production game. We then consider the payoff from participating in a collegial organization, the decision to join such an organization and the implications for sorting into

\footnotetext{
${ }^{1}$ Sportsmanship refers to behaviors such as being flexible, willingness to take on new responsibilities and not complaining about trivial matters. Civic virtue refers to behaviors such as punctuality, not taking time off, attending and participating in meetings. See Smith et al. (1984) and Podsakoff and MacKenzie (1997) for more examples.
} 
organizations with higher and lower levels of collegiality. Since organizations are long-lived, our analysis focuses on subgame perfect equilibria of the infinitely repeated stage game.

\subsection{Anonymous Market Basic Production Game}

Suppose two players, $\mathrm{i}$ and $\mathrm{j}$, are engaging in joint production. These players are individuals who are members of a production team within an organization. Exerting effort has costs and any output is evenly shared. We assume only two levels of effort, either positive with a cost of $c$ or zero. We assume that players will choose to exert effort in the normal state of the world, i.e. the long run future benefits incentivize effort for both players in the normal state of nature. In this case, output is $y$ and each player's present period profit is

$$
\pi_{\mathrm{i}}=\pi_{\mathrm{j}}=\frac{1}{2} \mathrm{y}-\mathrm{c}
$$

However, now consider the possibility that one or both players experience a shock making it impossible, or at least no longer optimal, to exert effort. In this case, that player exerts no effort, and in response, the other will either respond by exerting zero effort, or may simply not compensate by increasing effort to preserve production. As a result, output is zero. The following figure demonstrates the possible payoffs.

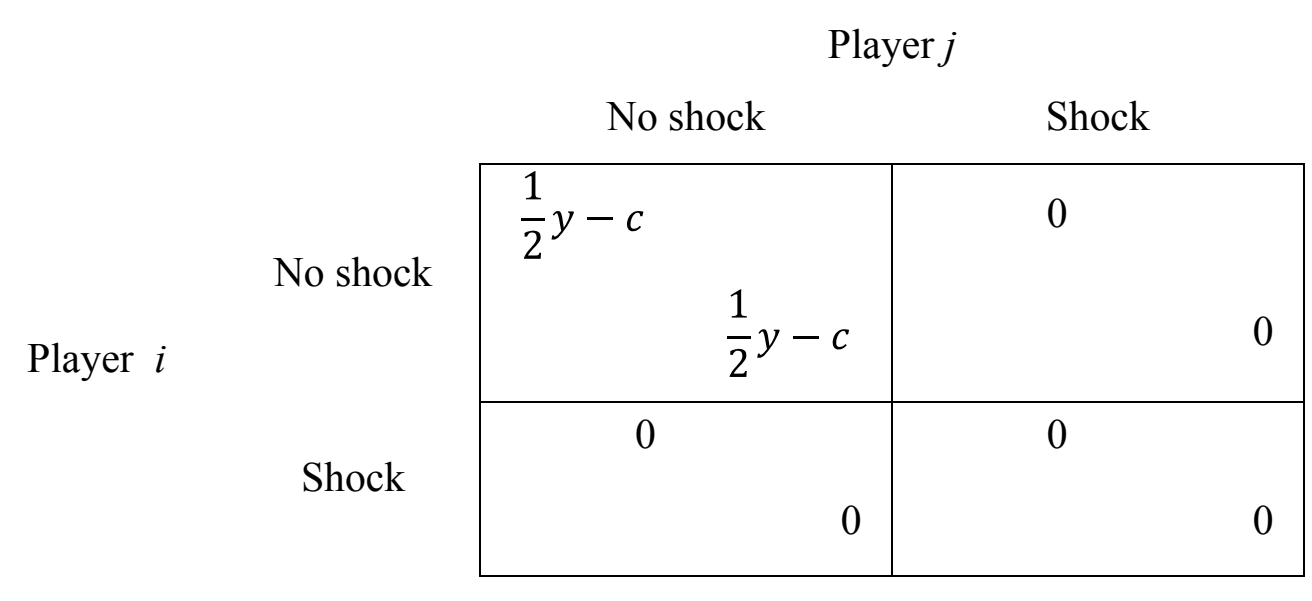

Figure 1.

Define $p_{i}$ and $p_{j}$ to be the probability that player $i$ and $j$ will experience a shock respectively. This generates the following expected current period profit.

$$
E \pi_{i}=E \pi_{j}=\left(1-p_{i}\right)\left(1-p_{j}\right)\left(\frac{1}{2} y-c\right)
$$

Over an infinite time horizon, expected profit is

$$
P V\left(E \pi_{i}\right)=P V\left(E \pi_{j}\right)=\frac{\left(1-p_{i}\right)\left(1-p_{j}\right)\left(\frac{1}{2} y-c\right)}{1-\delta}
$$

Note that we are not assuming the end of the game in the event of a shock. 


\subsection{Collegial Organization Production Game}

Now consider an alternative production process that takes place between colleagues or agents connected in some way that generates two specific synergies. First, effort by both players in this case generates $y>y$. Second, in the event of a shock to player $i$, if $j$ is a colleague, he may cover for player $i$ by exerting effort to preserve some output. As a result, output in this case is $\underline{y}$ where $y>y>\underline{y}$. In this collegial production game, output is as follows:

Player $j$

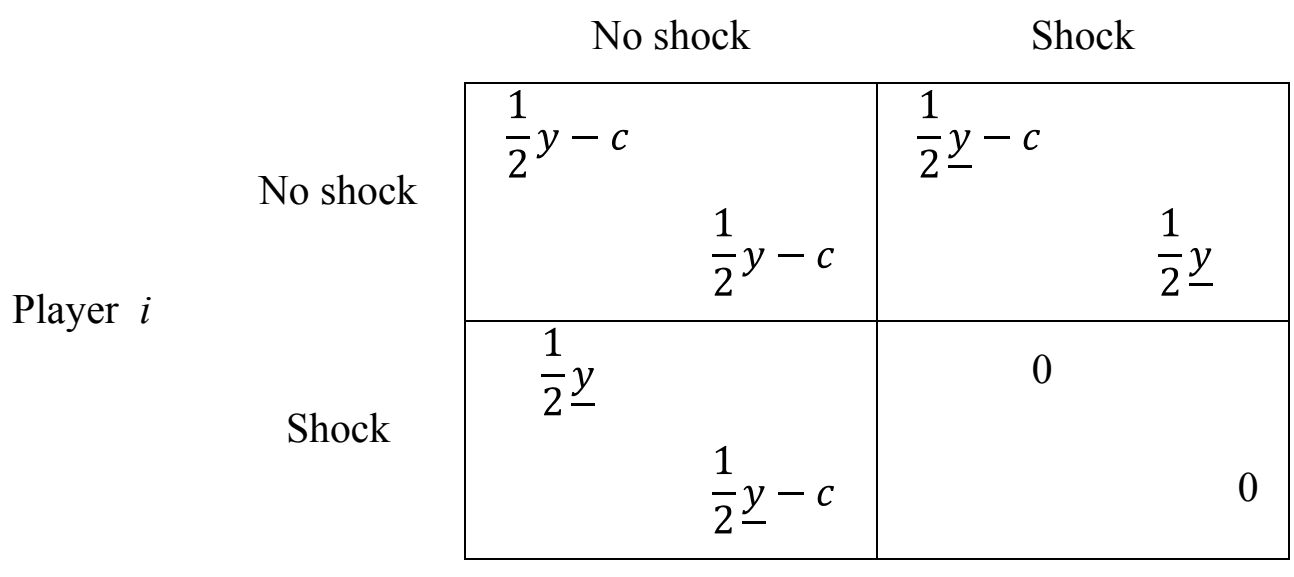

Figure 2.

Note that at this point, we are assuming that both costs and output are constant through time. This assumption could be relaxed by allowing costs to decline over time in a collegial organization. Similarly $y$ might rise over time. Based on the above assumptions, single period payoffs in this game to player $i$ are

$$
E \pi_{i}=1-p_{i} 1-p_{j} \frac{1}{2} \bar{y}-c+1-p_{j} p_{i} \frac{1}{2} \underline{y}+1-p_{i} p_{j} \frac{1}{2} \underline{y}-c+p_{i} p_{j}(0)
$$

Simplification and taking the present value of profit over an infinitely repeated game yields

$$
P V\left(E \pi_{i}\right)=\frac{1-p_{i} 1-p_{j} \frac{1}{2} y+\left(p_{i}+p_{j}-2 p_{i} p_{j}\right) \frac{1}{2} \underline{y-1-p_{i} c}}{1-\delta}
$$

\subsubsection{Entry Condition in a Collegial Organization Production Game}

Assume there exists an entry fee $E$ to join an organization with collegial production. This represents the costs of generating synergies that can raise joint output to $y$. Player $i$ will enter the collegial organization production game iff

$$
3^{\prime}-E \geq 2^{\prime}, \text { or } E \leq 3^{\prime}-\left(2^{\prime}\right)
$$

Note, however, this assumes that the players receive the payouts associated with their production. Define the critical value of $E_{i j}^{*}$ such that $E_{i j}^{*}=3^{\prime}-\left(2^{\prime}\right)$ which implies player $i$ will choose to join a collegial organization to produce with player $j$. This leads to: 


$$
\begin{aligned}
& =\frac{1-p_{i} 1-p_{j} \quad \frac{1}{2} y+\left(p_{i}+p_{j}-2 p_{i} p_{j}\right) \frac{1}{2} \underline{y}-1-p_{i} c-1-p_{i} \quad 1-p_{j}\left(\frac{1}{2} y-c\right)}{1-\delta} \\
& =\frac{1-p_{i} 1-p_{j} \frac{y-y}{2}+\left(p_{i}+p_{j}-2 p_{i} p_{j}\right) \frac{1}{2} \underline{y}-c 1-p_{i} p_{j}}{1-\delta}
\end{aligned}
$$

Player $i$ will enter a collegial organization iff $E \leq E_{i j}^{*}$ defined by equation (5). This can be considered the incentive compatibility constraint for collegial organization production. In the special case where $p_{i}=p_{j}$, this simplifies to

$$
E^{*}=\frac{(1-p)}{(1-\delta)} \frac{1-p}{2} y-y+p(\underline{y}-c)
$$

Since $y-y>0$ by assumption, a positive $E^{*}$ exists when $\underline{y}-c>0$, although this is not necessary. This simply regulates that effort produces a positive net output when a shock occurs.

Result 1: When $E^{*}$ rises, the possibility for collegial production expands. This occurs when $y$ and $y$ rise and $y$ falls making collegial output relatively larger. Also, as effort is more costly and the probability of shocks rise, collegial production is more costly and less likely to occur.

In other words, when the benefits from collegial production rises (when $y$ and $y$ rise), and the returns from non-collegial production falls, ( $y$ falls), there isa greater incentive for players to join collegial organizations. As such, the maximum entry fee at which players will still choose to join rises.

Before considering the equilibrium value of $E$ and using the potential matching outcome that results, we need to consider the sustainability of the collegiality game if it is entered into, and a shock actually occurs. Suppose a collegiality game is in place and player $j$ experiences a shock. Will player $i$ indeed exert effort to sustain $y$ ? We assure that if effort or insurance is not provided, the future is an anonymous market production game.

Player $i$ 's expected profit from exerting effort is:

$$
E \pi_{i} \text { effort }=\frac{1}{2} \underline{y}-c+\frac{1}{1+\delta} \frac{1-p_{i} \quad 1-p_{j} \quad \frac{1}{2} y+\left(p_{i}+p_{j}-2 p_{i} p_{j}\right) \frac{1}{2} \underline{y}-c 1-p_{i}}{1-\delta}
$$

$E \pi_{i}$ exit $=\frac{\left(1-p_{i}\right)\left(1-p_{j}\right)\left(\frac{y}{2}-c\right)}{1-\delta}$ as found in equation (2'). Thus Player $i$ will sustain the collegial game iff equation (7) $>$ equation $\left(2^{\prime}\right)$ or

$$
\begin{aligned}
& \frac{1}{2} \underline{y}-c+\frac{1}{1+\delta} \frac{1-p_{i} 1-p_{j} \frac{1}{2} y+\left(p_{i}+p_{j}-2 p_{i} p_{j}\right) \frac{1}{2} \underline{y}-c 1-p_{i}}{1-\delta}-\frac{1}{1+\delta} \frac{1-p_{i} 1-p_{j} \frac{y}{2}-c}{1-\delta}
\end{aligned}
$$

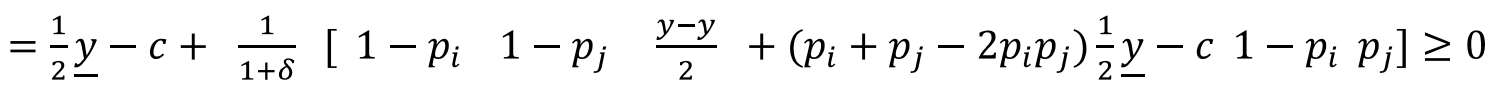

Equation (8) can be considered the participation constraint for collegial production. Note that the second term in brackets is precisely the condition found in equation (5) which must be positive for collegial production to have been entered into in the first place. The first term therefore produces a sufficient condition for collegial production to be sustained in the 
event of a shock; i.e. if $\frac{1}{2} \underline{y}-c \geq 0$, player $i$ will insure player $j$ in the event of a shock if player $i$ and player $j$ are colleagues.

Result 2: If conditions incentivize players to enter the collegial production game initially, it will be sustainable when player i's effort does not exceed his or her share of the output generated by covering for player j's shock.

That is, once the ex ante incentive to join is met, players will only continue to participate in this production game when the effort required of them when covering for the colleague's shocks is not overly costly relative to their share of the return from keeping production from falling to zero. Note that the incentive to join ex ante includes the benefits of the other player covering for them, but ex post, the game needs to be sustainable once a shock occurs and players must actually exert the effort to cover.

\subsection{Equilibrium}

Now we turn to the question of the equilibrium outcome. Our analysis will be to analyze the possibility of when a subgame perfect Nash equilibrium of the game can be supported. Specifically, what values of the entry fee will support such an equilibrium? A such, what will determine the value of $E$ ? How will players with differing shock probabilities match with one another?

Define two players as risky and safe where a risky player $R$ has a probability of a shock $p_{R}$ and a safe player $\mathrm{S}$ has probability of $p_{S}$, and $p_{R}>p_{S}$. Now suppose two similar types are in a potential collegial production game with entry fee $E^{*}$. Then, we have (9).

$$
E_{i i}^{*}=\frac{1}{1-\delta} \quad 1-p_{i}{ }^{2} \frac{y-y}{2}+p_{i} 1-p_{i} \quad \underline{y}-c \quad \text { where } \quad i=R, S
$$

We can also compare what a safe type $S$ would be willing to pay to match with a risky type $R$ and what a risky type $R$ would be willing to pay to match with a safe type $S$. These can be found in equation (10a) and (10b) respectively.

$$
\begin{aligned}
& E_{R S}^{* S}=\frac{1}{1-\delta} \quad 1-p_{S} \quad 1-p_{R} \frac{y-y}{2}+\left(p_{R}+p_{S}-2 p_{R} p_{S}\right) \frac{1}{2} \underline{y}-c 1-p_{S} p_{R} \\
& E_{R S}^{* R}=\frac{1}{1-\delta} \quad 1-p_{S} \quad 1-p_{R} \quad \frac{y-y}{2}+\left(p_{R}+p_{S}-2 p_{R} p_{S}\right) \frac{1}{2} \underline{y}-c 1-p_{R} p_{S}
\end{aligned}
$$

Since equations (10a) and (10b) only differ by the final term, it is straightforward to show that $E_{R S}^{* R}>E_{R S}^{* S}$. In other words, entry into the collegial production game is more attractive to a risky type pairing with a safe type than that pairing is to the safe type. From equation (9) we can also compare same type matches, i.e. $E_{S S}^{*}$ and $E_{R R}^{*}$. In comparing it is also straightforward to show that the first term in $E_{S S}^{*}$ exceeds that in $E_{R R}^{*}$, and the second term is larger when $p_{S}+p_{R}>1$. As such, $p_{S}+p_{R}>1$ is a sufficient but not necessary condition for $E_{S S}^{*}>E_{R R}^{*}$.

\subsubsection{Equilibrium Matching}

What conditions on these various surplus measures will generate positive assortative matching? For a safe type to match with themselves, it must be minimally true that they prefer another safe type to a risky type. Specifically, $E_{S S}^{*}>E_{R S}^{* S}$ (11a). But also, the surplus to a safe type from matching with another safe type must exceed what a risky type receives from 
pairing with a safe type, or $E_{S S}^{*}>E_{R S}^{* R}(11 \mathrm{~b})$. In other words, an entry fee can be set by a type $S$ sufficient to deter a type $R$.

Finally, it must also be the case that the net gains to a safe type from an assortative matching exceeds the gain a type $R$ receives from a non-assortative match with a type $S$. In other words,

$$
E_{S S}^{*}-E_{R S}^{* S}>E_{R S}^{* R}-E_{R R}^{*}
$$

Equation (11c) guarantees that there is no way to compensate a type $S$ for a match with a type $\mathrm{R}$, because the type $\mathrm{R}$ will not gain as much as the type $\mathrm{S}$ will lose. If equations (11a) (11b) and (11c) all hold, then there exists a value $E$ that will deter all matches other than $S-S$. Define this entry fee to be $E$. When will these conditions hold? Equation (11a) requires a comparison between equations (9) and (10a), or,

$$
\begin{aligned}
& E_{S S}^{*}-E_{R S}^{* S}=\frac{1}{1-\delta} \quad 1-p_{S}{ }^{2} \frac{y-y}{2}+p_{S} 1-p_{S} \quad \underline{y}-c \\
& -\frac{1}{1-\delta} \quad 1-p_{S} \quad 1-p_{R} \frac{y-y}{2}+\left(p_{R}+p_{S}-2 p_{R} p_{S}\right) \frac{1}{2} \frac{y}{-} \\
& -c 1-p_{S} p_{R}
\end{aligned}
$$

A comparison term by term can show that this is always positive. Thus, equation (11a) always holds. Equation (11b) requires a comparison between equations (9) and (10b), or,

$$
\begin{aligned}
E_{S S}^{*}-E_{R S}^{* R}= & \frac{1}{1-\delta} \quad 1-p_{S}{ }^{2} \frac{y-y}{2}+p_{S} 1-p_{S} \quad \underline{y}-c-1-p_{S} 1-p_{R} \frac{y-y}{2} \\
& -\left(p_{R}+p_{S}-2 p_{R} p_{S}\right) \frac{1}{2} \underline{y}+c 1-p_{R} p_{S}
\end{aligned}
$$

Again, a term by term comparison ensures this holds for all $p_{R}>p_{S}$. Finally consider equation (11c). A careful analysis, found in appendix A, reveals that this condition holds iff

$$
\left(\frac{y-y}{2}\right)\left(P_{S}-P_{R}\right)^{2}+\underline{y}-C \quad\left(P_{S}-P_{R}\right)^{2}>0
$$

Note that if the entry fee is paid and players are engaged in collegial production, the benefits $y-y$ occur with both types of players as long as there are no shocks and is shared, thus divided by two. However, $\underline{y}$ is generated in the event of a shock which occurs when either one of the players experiences a shock; output is shared but it is also accrued in both cases. Finally, the costs are paid only by the player who does not experience a shock; they are not shared but they also occur only when it is not the player's own shock.

From (12) it is clear that associative matching is more likely when the difference in probabilities is greater; i.e., players are sufficiently different. Also, as expected, when the gains to collegial production relative to the standard production game rise, we will see more associative matches. And finally, when the output that can be salvaged by the intervention of the colleague's efforts in the event of a shock is larger relative to the costs of doing so, then this matching collegial production game is sustainable. Note that it is possible for the costs to outweigh the one-time benefits (i.e., term two in (12) could be negative) if the benefits from synergies in the absence of the shocks are large enough. Thus, a player will exert costly effort to his or her immediate detriment in order to sustain the collegial game in the long run. 


\subsubsection{Extension: Productivity Benefits from Collegiality}

One question that might arise is how we might interpret $\mathrm{E}$ as an entry fee. As specified above, if $\mathrm{E}$ is interpreted as an entry fee, the conditions in $(11 \mathrm{a}, \mathrm{b}, \mathrm{c})$ assure assortative matching. If this entry fee is interpreted as acculturation to corporate policies, procedures and workplace collegiality, then although it is a consumable, it should also have productivity implications. In other words, organizations that invest in culture and collegiality will reach higher levels of output when collegial production occurs; thus the difference in $y-y$ and the value of $\underline{y}$ represent the benefits from collegiality.

Suppose instead of types being differentiated by their probability of facing a shock, players are differentiated on another dimension such that when similar types match together they produce a greater level of $y$. In other words, synergies from having similar attributes make like-players more productive in the positive state of the world. Specifically, define $y>$ $y$ to be the output when player $i$ matches with $i$ or when $j$ matches with $j$, and no shock occurs, and define $y$ to be the output when a type i matches with a type $\mathrm{j}$. Suppose all types experience the same probability of a shock p, so the only factor at play is the match. In this case, when similar types match, they would be willing to pay an entry fee found in (13a). Denote this fee $E_{i i}^{*}$.

$$
E_{i i}^{*}=\frac{(1-p)}{(1-\delta)} \frac{1-p}{2} y-y+p(\underline{y}-c)
$$

While that fee for dissimilar types can be found in (13b).

$$
E_{i j}^{*}=\frac{(1-p)}{(1-\delta)} \frac{1-p}{2} y-y+p(\underline{y}-c)
$$

Since $(13 a)>(13 b)$, it is possible to set an entry fee that will only attract similar types. Specifically, assortative matches will occur when

$$
E_{i i}^{*}>E>E_{i j}^{*}
$$

This can be interpreted in the following way. A company full of type i's will then only attract i's while a company of j's will attract j's and they can both have the same fee. No type is better or worse than the other, but this could be considered as scenario of personality or other attributes that match well together.

\section{Discussion}

Our analysis yields a positive correlation between corporate culture and collegiality. Some organizations will have strong culture and high collegiality while others have weak culture and low collegiality. Since high collegiality in our model is associated with high mutual insurance, the model also explains the observed correlation between the strength of corporate culture and the reliability of firm performance. Since imbibing the corporate culture of an organization takes time and effort, it is costly to join a collegial organization and reap the benefits of mutual insurance that it provides. As a result, individuals of distinct types sort into organizations with different costs of learning the corporate culture.

These results of the model are consistent with a well-established management literature on organizational culture (Barney, 1986). In this literature, attempts to explain the sustained superior financial performance of firms like IBM, Hewlett - Packard, Procter \& 
Gamble and McDonald's have focused on the managerial values and beliefs embodied in these firms organizational cultures. An influential qualitative study by Peters and Waterman (1982) of 62 American firms leads them to suggest that firms with sustained superior financial performance typically are characterized by a strong set of core managerial values that define the ways they conduct business. They find that the stronger the culture and the more it was directed toward the marketplace, the less the need for policy manuals, organization charts, or detailed procedures and rules. In these companies, people way down the line know what they are supposed to do in most situations because the handful of guiding values is crystal clear. In contrast, poorly performing companies often have watered down cultures.

Peters and Waterman find that shared values in the "excellent" companies (companies with sustained superior financial performance) are clear, in large measure, because the mythology is rich. An important finding is that excellent companies are marked by very strong cultures, so strong that you either buy into their norms or get out. There is no halfway house for most people in these companies. This notion is well-captured by the following quote: "One very able consumer marketing executive told us, 'you know, I deeply admire Procter \& Gamble. They are the best in the business. But I don't think I could ever work there". Transmitting and imbibing the values of the company takes a significant amount of effort and resources and a key role of the chief executive is to manage the values of the organization. Firms sometimes have distinctive ways of referring to their organizational norms, such "the HP Way."

A caveat to the quantitative testing of some of the implications of the model could be the measurement of collegiality and the costs of learning organizational norms. However, the productivity implications of collegiality and corporate culture have not been examined empirically by the industrial organization literature and seems a rich area for further research ${ }^{2}$.

\section{References}

Bateman, T. S., and Organ, D. W. (1983), Job Satisfaction and the good soldier: The relationship between affect and employee "citizenship", Academy of Management Journal, Vol. 26, pp. 587-595.

Barney, J. B. (1986), Organizational culture: Can it be a source of sustained competitive advantage? Academy of Management Review, 11, pp. 656-665.

Besley, T. and Ghatak, M. (2005), Competition and Incentives with Motivated Agents, American Economic Review, Vol. 95, pp. 616-636.

Brown, S., Gray, D., McHardy, J. and K. Taylor (2015), Employee Trust and workplace performance, Journal of Economic Behavior \& Organization, 116, pp. 361-378.

Camerer, C. and A. Vepsalainen (1998), The Economic Efficiency of Corporate Culture, Strategic Management Journal, Vol. 9, Summer, pp. 115-126.

Carillo, J. D. and D. Gromb (1999), On the Strength of Corporate Cultures, European Economic Review, Vol. 43, pp. 1021-1037.

Chatman, J. A. (1991), Matching People and Organizations: Selection and Socialization in Public Accounting Firms, Administrative Science Quarterly, Vol. 36, pp. 459-484.

Coleman, J. (2013), Six Components of a Great Corporate Culture, Harvard Business Review, May 2013, https://hbr.org/2013/05/six-components-of-culture

Cremer, J. (1993), Corporate Culture and Shared Knowledge, Industrial and Corporate Change, Vol. 3, pp. 351-386.

Dranove, D., Ramanarayan, S. and Rao, H. (2006), The Substance of Style: A Study of Practice Styles of Ob? Gyn Practice Specialists in Florida, Working Paper, Kellog

\footnotetext{
${ }^{2}$ A recent paper by Brown et. al. (2015) is a notable contribution along these lines.
} 
School of Management, Northwestern University, http://www.anderson.ucla.edu/faculty/subramaniam.ramanarayanan/Papers/Practice $\% 20$ Variations\%20Paper.pdf

Flamholtz, E. and Randle, Y. (2011), Corporate Culture: The Ultimate Strategic Asset, Stanford University Press, Stanford, California.

Hermalin, B. E. (2001), Economics and Corporate Culture, In: C. L. Cooper, S. Cartwright and P. C. Earley (eds.), The International Handbook of Organizational Culture and Climate, New York: John Wiley \& Sons.

Kreps, D. M. (1990), Corporate Culture and Economic Theory, In: J. E. Alt and K. A. Shepsle (eds.), Perspectives on Positive Political Economy, Cambridge: Cambridge University Press.

Lazear, E. P. (1995), Corporate Culture and Diffusion of Values, In: R. Siebert (ed.), Trends in Business Organization: Do Participation and Cooperation Increase Competitiveness? Tubingen: Mohr.

Peters, T. J. and R. H. Waterman (1982), In search of excellence: lessons from America's best run companies, Harper \& Row Publishers, New York.

Podsakoff, P. M., Ahearne, M. and MacKenzie, S. B. (1997), Organizational citizenship behavior and quantity and quality of work group performance, Journal of Applied Psychology, Vol. 82, pp. 262-270.

Podsakoff, P. M., and MacKenzie, S. B. (1997), The impact of organizational citizenship behaviors on organizational performance: A review and suggestions for future research, Human Performance, Vol. 10, pp. 133-151.

Rob, R. and Zemsky, P. B. (2002), Social Capital, Corporate Culture and Incentive Intensity, Rand Journal of Economics, Vol. 33, pp. 243-257.

Schien, E. H. (1985), Organizational Culture and Leadership, San Francisco: Jossey-Bass.

Smith, C. A., D. W. Organ, and Near, J. P. (1983), Organizational Citizeship Behavior: Its Nature and Antecedents, Journal of Applied Psychology, Vol. 68, No. 4, pp. 653-663.

Walz, S. M. and Niehoff, B. P. (1996), Organizational citizenship behaviors and their effect on organizational effectiveness in limited-menu restaurants, Academy of Management Best Paper Proceedings, pp. 307-311. 
Appendix A

Recall that equation (11c) is required for it to be impossible to compensate a player and incentivize a non-associative match.

$$
\begin{aligned}
& E_{S S}{ }^{*}-E_{R S}{ }^{* S}>E_{R S}{ }^{* R}-E_{R R}{ }^{*} \\
& \text { Or, } E_{S S}{ }^{*}+E_{R R}{ }^{*}>E_{R S}{ }^{* S}-E_{R S}{ }^{* R}
\end{aligned}
$$

meaning that the total surplus generated by associative matching, represented by the left hand side, exceeds that generated by non-associative matching, represented on the right hand side. From (9) we find $E_{S S}{ }^{*}$ and $E_{R R}{ }^{*}$ and sum them to find

$$
\begin{aligned}
E_{S S}^{*}+E_{R R}^{*} & =\frac{1}{1-\delta}\left[\frac{y-y}{2}\left(\left(1-P_{S}\right)^{2}+1-P_{R}^{2}\right)+\underline{y}-C \quad P_{S} 1-P_{R}+P_{R}-P_{S}\right] \\
& =\frac{1}{1-\delta}\left[\frac{y-y}{2} 2-2 P_{S}+P_{S}^{2}-2 P_{R}+P_{R}^{2}+\underline{y}-C \quad P_{S}+P_{R}-2 P_{S} P_{R}\right]
\end{aligned}
$$

From (10a) and (10b) we find $E_{R S}{ }^{* S}$ and $E_{R S}{ }^{* R}$ and sum them to find

$$
E_{S R}^{* S}+E_{S R}^{* R}=\frac{1}{1-\delta}\left[\frac{y-y}{2}\left(2\left(1-P_{S}\right)\left(1-P_{R}\right)+\underline{y}-C \quad P_{R}+P_{S}-2 P_{R} P_{S}\right]\right.
$$

Combing (A1) and (A2), the condition in (11c) becomes

$$
\begin{aligned}
& \frac{1}{1-\delta}\left[\frac{y-y}{2} 2-2 P_{S}+P_{S}^{2}-2 P_{R}+P_{R}^{2}+\underline{y}-C \quad P_{S}+P_{R}-2 P_{S} P_{R}\right] \\
& >\frac{1}{1-\delta}\left[\frac{y-y}{2}\left(21-P_{S}-P_{R}+P_{S} P_{R}+\underline{y}-C \quad P_{R}+P_{S}-2 P_{S} P_{R}\right]\right.
\end{aligned}
$$

Re-arranging and simplifying this yields

$$
\left(\frac{y-y}{2}\right)\left(P_{S}-P_{R}\right)^{2}+\underline{y}-C \quad\left(P_{S}-P_{R}\right)^{2}>0
$$

